\title{
The paranasal sinuses: three-dimensional reconstruction, photo-realistic imaging, and virtual endoscopy
}

\author{
S. Kapakin \\ Department of Anatomy, Faculty of Medicine, Atatürk University, Erzurum, Turkey \\ [Received: 31 October 2015; Accepted: 4 January 2016]
}

Background: The purpose of the study was to create computer-aided design models of the paranasal sinuses (frontal, maxillary, and sphenoid) and to perform virtual endoscopy (VE) to them by using virtual reality modelling language technique.

Materials and methods: The visible human dataset was used as the input imaging data. The Surfdriver software package was applied on these images to reconstruct the paranasal sinuses as 3-dimensional (3D) computer-aided design models. These models were post-processed in Cinema 4D to perform the photorealistic imaging and VE of the paranasal sinuses.

Results: The volumes of the maxillary sinuses were $24747.89 \mathrm{~mm}^{3}$ on the right and $29008.78 \mathrm{~mm}^{3}$ on the left. As for sphenoidal sinuses, an enormous variation was seen between the right and left cavities. The sphenoidal sinuses were $1995.90 \mathrm{~mm}^{3}$ on the right and $10228.93 \mathrm{~mm}^{3}$ on the left while the frontal sinuses were $20805.67 \mathrm{~mm}^{3}$ on the right and $18048.85 \mathrm{~mm}^{3}$ on the left. The largest sinus was left maxillary sinus by volume. Right frontal sinus was the largest sinus by surface area. It was calculated as $6002.73 \mathrm{~mm}^{2}$. Our methodological outcomes proved that Surfdriver and Cinema $4 D$ pair could be reliably used for $3 D$ reconstructions, photo realistic imaging and creating 3D virtual environments from the serial sections of the anatomical structures. Conclusions: This technique allows students, researchers, and surgeons to perform noninvasive visualisation, simulation, and precise quantitative measurements of internal structures of the body. It was developed as a complementary tool for endoscopic surgery. It could be especially preferable for the patients who could not tolerate flexible or rigid endoscopy. (Folia Morphol 2016; 75, 3: 326-333)

Key words: paranasal sinuses, 3-dimensional reconstruction, photorealistic imaging, virtual reality modelling language, virtual endoscopy

\section{INTRODUCTION}

Creating 3-dimensional (3D) anatomical reconstructions from the spatial arrangement of the consecutive cross-sectional images dates back to the late 70s [24]. Since then, technology has evolved continuously [36]. However, the impact of these techniques on real life remains limited, because generating 3D models is quite intricate. Three-dimensional imaging process needs identifying regions on each cross-sectional image that delineates the anatomical objects. Otherwise we could not bring to light their surfaces or take off objects concealing the others behind [42].

Address for correspondence: Dr S. Kapakin, Department of Anatomy, Faculty of Medicine, Atatürk University, 25240 Erzurum, Turkey, tel: +90 442344 6626, ext: 6626, fax: +90442 344 6528, e-mail: sametkapakin@gmail.com 
The computer technology, enabling the visualisation of serial sectional images on a display, made revolutionary impact on the 3D reconstruction techniques. The computer-aided 3D reconstruction techniques rapidly spread in biomedical researches, parallel to the rapid advances of computer performance.

Computer-aided 3D models provide a valuable tool for examining complicated structural relationships and morphological processes in biomedical studies, medical diagnosis and treatment [48]. Morphometric and volumetric characteristics of the parts of the human body are of great importance in the designing and manufacturing of their anatomical models and also in the interpretation and presentation of experimental results [16]. These models enable students, researchers and surgeons to better understand complex structures and facilitate diagnosis and treatment.

Endoscopic surgery of the paranasal sinuses $[2,18,37]$ is regarded as a contemporary and successful approach that plays an important role in ear, nose and throat treatment. Traditionally, preoperative planning is based on imaging modalities such as X-ray, computed tomography (CD) and magnetic resonance imaging (MRI), as well as flexible or rigid endoscopy [3]. The surgeons build 3D structures mentally in their head by benefiting 2D images prior to the surgical intervention. They will not be able to foresee trouble during surgery and take measures where necessary prior to surgery. Recently, virtual endoscopy (VE) has drawn the otolaryngologists' much attention in terms of the paranasal sinuses $[6,7,47]$. VE uses very sophisticated technologies such as computer and graphic systems [35]. Actually, this imaging modality was applied on different parts of the human body such as the urinary tract [26], the oesophagus [12], the colon [11, 39], and tracheobronchial system [20, $34,49]$. We have created patient-specific 3D models of the paranasal sinuses to be used by both radiologist and otolaryngologist for VE with using virtual reality modelling language (VRML) technique. They can evaluate these structures in terms of diagnosis, treatment, and surgery. Also, they can better conceive of the complicated structures and can take measures against adverse conditions.

The purpose of the study was to create computeraided design models of the paranasal sinuses (frontal, maxillary, and sphenoid) and to perform VE to them by using VRML technique.

\section{MATERIALS AND METHODS}

\section{Data source}

In the study, the visible human male dataset was used. This dataset has three distinct components: CT, MRI and anatomical cryosections [1, 46]. High resolution colour anatomical cryosections were preferred because these images have higher quality than the others. This dataset provides a standard for the acquisition and use of data [23].

\section{Cryosectional image features of the visible human male dataset}

Frozen corpse was cut away from head to toe in $1 \mathrm{~mm}$ thickness and colour cryosectional images were taken. 24-bit colour cryosectional images had a resolution of $2048 \times 1216$ pixels [46].

Three-dimensional computer aided design models of the paranasal sinuses

The key point of our work is to identify the spatial size of the paranasal sinuses and to create their surface models (computer-aided design models). These models are suitable for various purposes such as VE, pre-operative simulation, real time rendering and post-operative analysis $[8,43]$.

The process of creating computer-aided design models of the paranasal sinuses could be divided into three steps that cover registration, segmentation and surface reconstruction. Registration was to bring the consecutive sections to the position in space according to coordinates XYZ. Segmentation was the process of recognising and drawing boundaries of the paranasal sinuses within an image. It requires expert knowledge of anatomy. It was an indispensable step in most of the processes that were applied to medical imaging [52]. Reconstruction was to bring together parts of the paranasal sinuses labelled on consecutive sections. These processes gave computer-aided design models of the paranasal sinuses (Fig. 1). These steps were performed by Surfdriver and 3D-Doctor software.

\section{Development of the photorealistic models of the paranasal sinuses}

The computer-aided design models were transferred into Cinema 4D so as to be used by the advanced render module. The module enabled us to create the photorealistic models of the paranasal sinuses which were spectacularly realistic (Fig. 2). This step was performed by Cinema 4D software. 


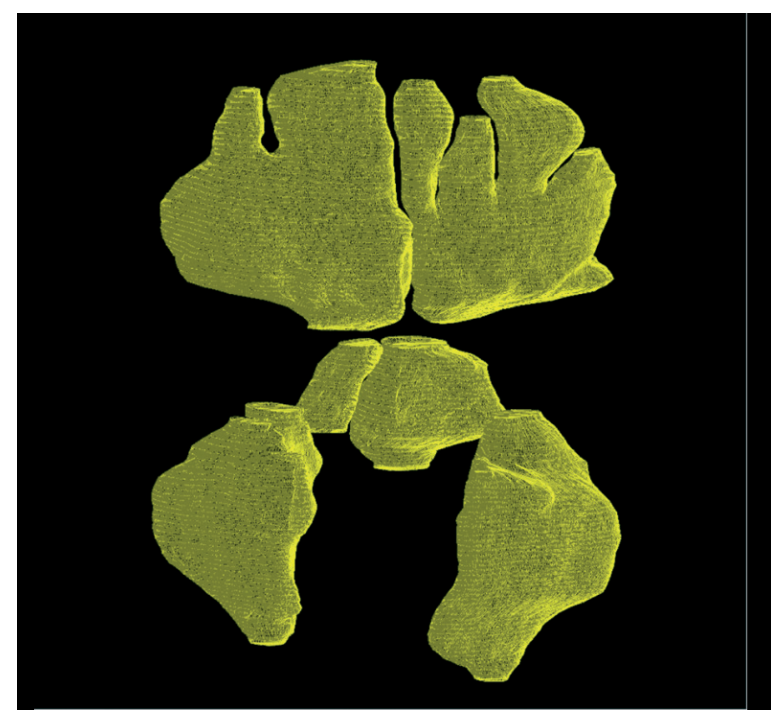

Figure 1. Three-dimensional reconstructions of the paranasal sinuses (frontal, maxillary, and sphenoid sinuses) as a wireframe.

\section{Development of VRML forms of the paranasal sinuses for virtual endoscopy}

The computer-aided design models of the paranasal sinuses could be converted into VRML format for VE (Figs. 3-5). This step was performed by Cinema 4D software. These models could be seen in Cortona 3D Viewer.

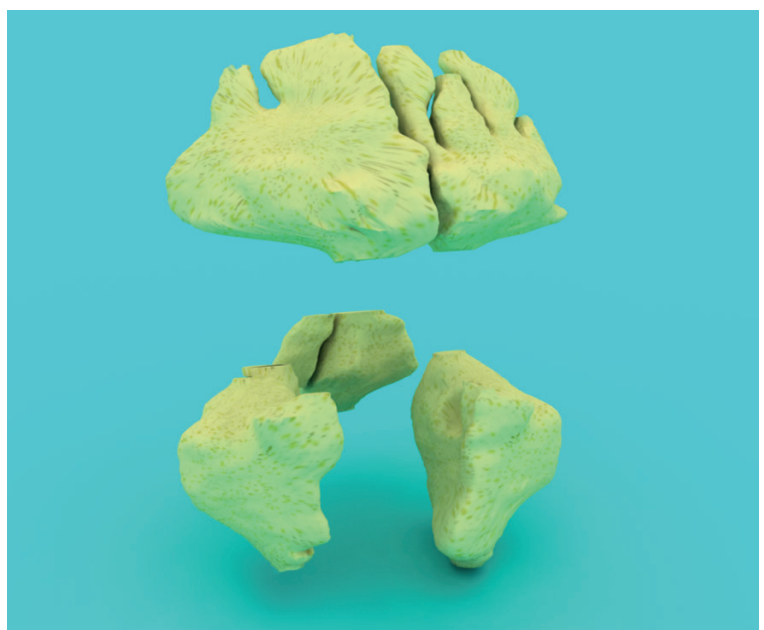

Figure 2. The photorealistic view of the paranasal sinuses (frontal, maxillary, and sphenoid sinuses) rendered by using Cinema 4D software. All the anatomical details belonging to the paranasal sinuses (frontal, maxillary, and sphenoid sinuses) can be seen with high sensitivity.

\section{Morphometric, surface and volumetric calculations of the paranasal sinuses}

In order to make measurements on the models and calculate surface areas and volumes of the 3D models, the tools of the Surfdriver and 3D Doctor software packages were used. The automated volume

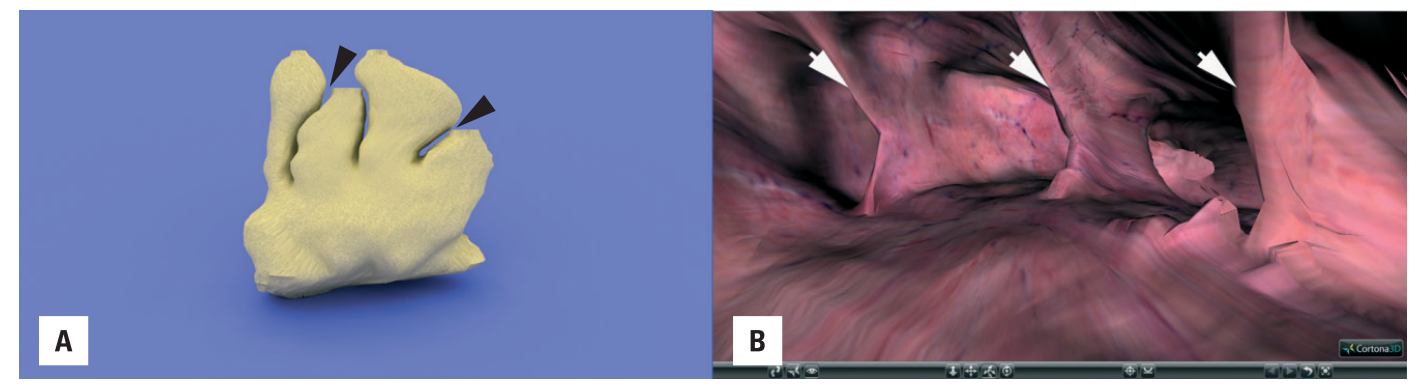

Figure 3. A. External surface of the frontal sinus with septations (black arrows); B. Virtual endoscopic view of the frontal sinus with septations (white arrows).

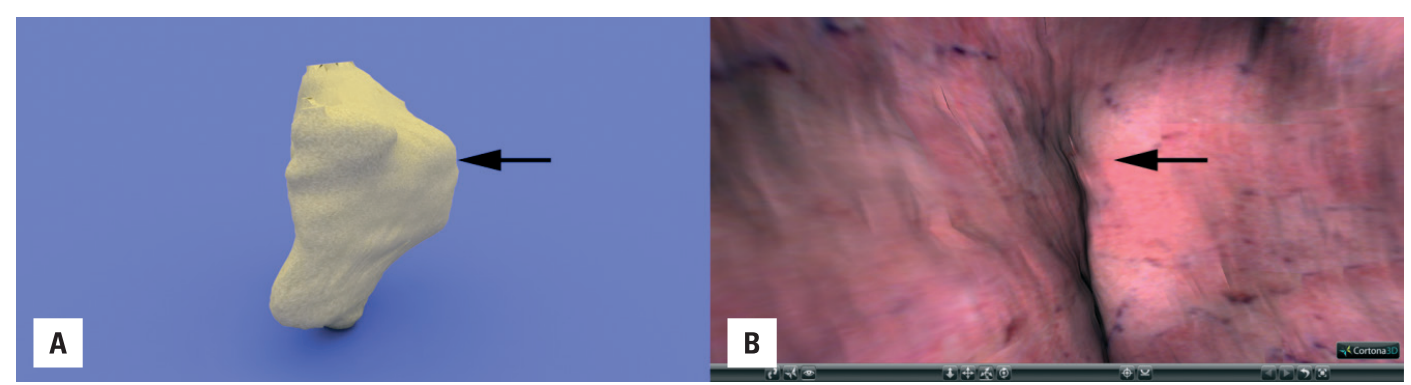

Figure 4. A. External surface of the apex of the maxillary sinus (black arrow); B. Virtual endoscopic view of the apex of the maxillary sinus (black arrow). 


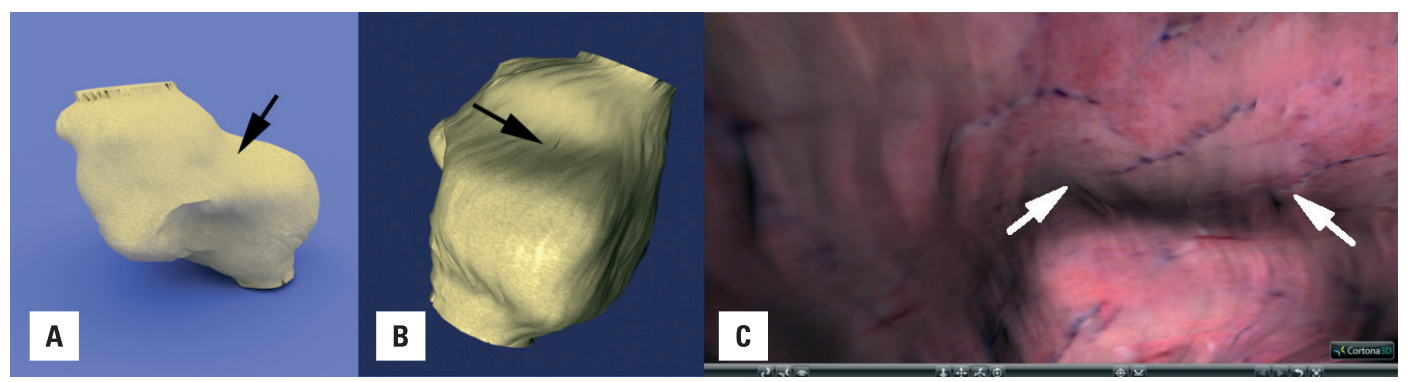

Figure 5. A, B. External surface of the sphenoid sinus with the depression caused by hypophyseal fossa (black arrows); C. Virtual endoscopic view of the sphenoid sinus with the bulging caused by the hypophyseal fossa (white arrows).

calculation of each sinus was performed as follows: the volume of the each section was calculated by multiplying the area of interest on each section by the section thickness. Then the volumes of the paranasal sinuses were obtained by summing all volumes on each section via tools of Surfdriver and 3D Doctor

Table 1. The automated volume calculations for paranasal sinuses $\left[\mathrm{mm}^{3}\right]$

\begin{tabular}{lcc}
\hline & Right & Left \\
\hline Frontal sinuses & 20805.67 & 18048.85 \\
Maxillary sinuses & 24747.89 & 29008.78 \\
Sphenoid sinuses & 1995.90 & 10228.93 \\
\hline
\end{tabular}

Table 2. The estimated volume calculations for the paranasal sinuses $\left[\mathrm{mm}^{3}\right]$

\begin{tabular}{lcc}
\hline & Right & Left \\
\hline Frontal sinuses & 20088.18 & 17894.65 \\
Maxillary sinuses & 24219.64 & 29626.90 \\
Sphenoid sinuses & 1991.90 & 10728.82 \\
\hline
\end{tabular}

Table 3. The surface areas of the paranasal sinuses $\left[\mathrm{mm}^{2}\right]$

\begin{tabular}{lcc}
\hline & Right & Left \\
\hline Frontal sinuses & 6002.73 & 5579.69 \\
Maxillary sinuses & 5349.73 & 5917.04 \\
Sphenoid sinuses & 1048.31 & 2828.41 \\
\hline
\end{tabular}

software packages. In addition, the estimated volume calculation of each sinus was performed using the following equation: (maximum craniocaudal distance $\times$ maximum anteroposterior distance $\times$ maximum transverse distance $\times 0.5$ ).

\section{RESULTS}

Using the methods described above, we built the models of the paranasal sinuses (frontal, maxillary, and sphenoid) within the head of the male visible human.

\section{Morphometric, surface and volumetric results}

The automated and estimated volumes of each sinus are given in Tables 1 and 2 . The surface area of each sinus is given in Table 3. The morphometric measurements of each sinus are given in Table 4 . The volumes of the maxillary sinuses were $24747.89 \mathrm{~mm}^{3}$ on the right and $29008.78 \mathrm{~mm}^{3}$ on the left of the cadaver. As for sphenoidal sinuses, an enormous variation was seen between the right and left cavities. The sphenoidal sinuses were $1995.90 \mathrm{~mm}^{3}$ on the right and $10228.93 \mathrm{~mm}^{3}$ on the left of the cadaver while the frontal sinuses were $20805.67 \mathrm{~mm}^{3}$ on the right and $18048.85 \mathrm{~mm}^{3}$ on the left of the cadaver. The largest sinus was left maxillary sinus by volume. Right frontal sinus was the largest sinus by surface area. It was calculated as $6002.73 \mathrm{~mm}^{2}$. The dimensions of all paranasal sinuses were $40.96 \times 45.00 \times 26.28 \mathrm{~mm}$ for the right maxillary sinus, $45.05 \times 51.00 \times 25.79 \mathrm{~mm}$ for the left maxillary sinus, $14.98 \times 50.00 \times 53.64 \mathrm{~mm}$

Table 4. The morphometric measurements of the paranasal sinuses [mm]

\begin{tabular}{|c|c|c|c|c|c|c|}
\hline \multirow[t]{2}{*}{ Parameters } & \multicolumn{2}{|c|}{ Frontal } & \multicolumn{2}{|c|}{ Maxillary } & \multicolumn{2}{|c|}{ Sphenoid } \\
\hline & Right & Left & Right & Left & Right & Left \\
\hline Antero-posterior distance & 14.98 & 17.39 & 40.96 & 45.05 & 21.67 & 32.17 \\
\hline Cranio-caudal distance & 50.00 & 46.00 & 45.00 & 51.00 & 16.00 & 28.00 \\
\hline Transverse distance & 53.64 & 44.74 & 26.28 & 25.79 & 11.49 & 23.82 \\
\hline
\end{tabular}


for right frontal sinus, $17.39 \times 46.00 \times 44.74 \mathrm{~mm}$ for left frontal sinus, $21.67 \times 16.00 \times 11.49 \mathrm{~mm}$ for right sphenoid sinus, and $32.17 \times 28.00 \times 23.82 \mathrm{~mm}$ for left sphenoid sinus.

\section{Methodological results}

Our methodological outcomes proved that Surfdriver and Cinema 4D pair could be reliably used for 3D reconstructions, photorealistic imaging and creating 3D virtual environments from the serial sections of the anatomical structures in anatomical cryosections. The technique was capable of revealing anatomical structures' configuration, spatial position and neighbourhood relationships three dimensionally and interactively. It provided an efficient tool to make morphological measurement, volumetric analysis and VE. This technique could shed light on the development of new surgical techniques while providing multifaceted approach to complex structures.

\section{Educational results}

VE training enabled students, researchers, and inexperienced surgeons to gain proficiency in anatomy of the paranasal sinuses and in technical and conceptual aspects of VE of the paranasal sinuses.

\section{DISCUSSION}

Mysterious structure and function of the paranasal sinuses has attracted the attention of many researchers $[7,21,47]$. Unfortunately, the anatomy and physiology of the paranasal sinuses are still not fully understood. It has not been gone beyond the structure revealed by conventional imaging methods. Otolaryngologists have tried to discover ideal approach to surgery of the paranasal sinuses throughout their career in order to provide a better perspective and to relieve the symptoms of the patient [3].

Paranasal sinus CT scans are considered as a gold standard for the evaluation of the paranasal sinuses $[15,51]$. With the advent of helical CT in the late 1980s, more detailed images were obtained in a short time [55]. Also, the coronal and sagittal images of the same quality could be created from the images obtained axially. The coronal images gave more anatomical information to otolaryngologists in terms of the direction in which the intervention was carried out. It helped to look through a window so as to provide a better understanding [3]. The use of MRI has provided a better view of the soft tissue while reducing artefacts [33]. MRI has become an impor- tant imaging modality in the evolution of malignant diseases and complications of inflammatory diseases of the paranasal sinuses [15].

Real endoscopy is invasive and uncomfortable for the patients. It can cause serious side effects such as infection, bleeding, and perforation [7]. In minimally invasive surgery, surgeons place various instruments into surgical region. Visual feedback of the instruments is limited to the image taken by an eyepiece of the endoscope. Most endoscopes provide only monocular image [54].

In this study, VE is a cutting edge technology which allows showing not only the inner surface of the paranasal cavities and but also the presence of the transmural lesions of the paranasal sinuses (Figs. 2-5). It is an utterly non-invasive and safe method in which we could examine paranasal sinuses by using high-quality images. Furthermore, It allowed access to places inaccessible to conventional endoscopy $[9,22]$. The surgical procedure can be repeated ad libitum on this method. Therefore it can be used as an educational tool [13], as well as in diagnosis [17] and preoperative planning [50]. VE could be applicable in the long-term follow-up of patients with paranasal sinuses disease [26]. Nevertheless images were not completely free from artefacts and distortions. It required specialist knowledge and experience to distinguish. This technique provided the surgeon with adequate preoperative imaging, which facilitated the surgical procedures [9].

In our technique, we revealed the exact spatial location of the paranasal sinuses. We determined the easiest and surest way to reach them with coordinates. We offered the opportunity to detect abnormal and pathological structures in this region. If necessary, we analysed internal surfaces of the paranasal sinuses and presence of transmural lesions by taking them out from the body (Fig. 6). We created higher resolution and more detailed images than previous studies $[40,54]$.

The cryosectional images, which had higher spatial resolution than the images obtained from routinely used paranasal CT scans or MRI scans, were preferred. These images allowed distinguishing fine details. The paranasal cavities were filled with methylene blue in the stage of cadaver preparation. This situation created a higher contrast resolution. This made it easier to be able to discriminate different densities. A special module was applied on the models to be able to acquire photorealistic images in cinema 4D software. 


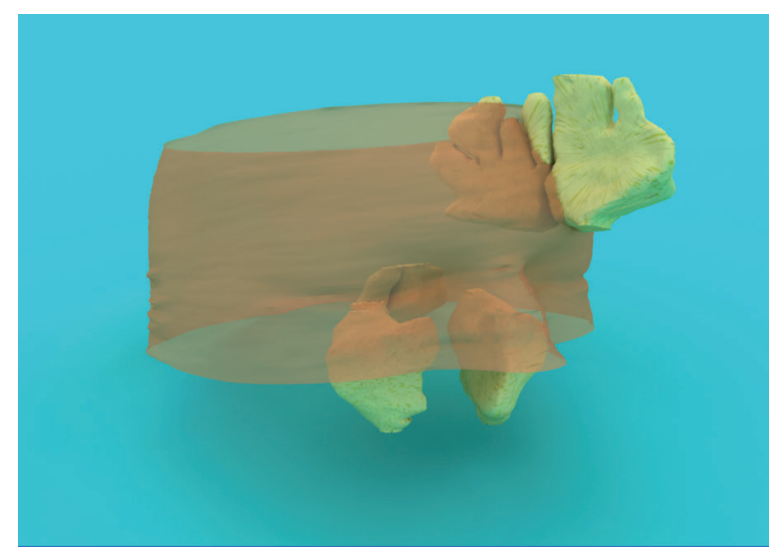

Figure 6. Evaluation of the transmural lesions of the paranasal sinuses (frontal, maxillary, and sphenoid sinuses) by taking them out from body photorealistically.

We used manual segmentation [27-29] to create $3 \mathrm{D}$ models of the paranasal sinuses in this study. The segmentation is gaining more importance every day. It is the most critical step in creating 3D model. It delivers more accurate results by identifying the exact boundary of each structure on the medical image. Manual segmentation is time-consuming and laborious, therefore, may not be appropriate for large data. However, manual segmentation still remains the gold standard. It is used either to collect information on normal anatomical structures in healthy individuals or to detect changes in sick individuals. There should be at least two separate tracers to avoid personal mistakes. Manual segmentation is used as a reference for evaluating the reliability and validity of the automatic segmentation. Automatic segmentation $[14,56]$ is faster than manual segmentation and can be applied on large data. There are advocate [4] and critic [10] of the automatic segmentation in terms of normalisation procedures and susceptibility to minor changes [53].

There were many computer-based visualisation techniques for displaying the complex anatomical structures and collecting the quantitative data in medicine. However, most of them worked on only a local computer. This situation prevented the use of software on a different computer. In our technique, it was possible for users to apply all features of software and to perform VE wherever the internet is available [38].

In the evaluation of the paranasal sinuses, the measurement of the volumes of the cavities in the paranasal sinuses is the most important index, but it is not so easy to do. The dimensions of the paranasal sinuses show great differences between individuals. The size of the paranasal sinuses were calculated in different ways. Some researchers calculated them by directly giving various substances [31]; others calculated them by using different imaging modalities such as CT [44] and MRI [5]. Theoretically first technique provided accurate information about the size of the paranasal sinuses, but it could not be implemented in a living organism. Moreover, giving substance into the paranasal cavities was technically arduous task because of the anatomical complexity of the paranasal sinuses.

The results of the maxillary sinus volumes in this study were consistent with those in the previous studies $[19,25,31,32,41,44,45]$. The mean values of the maxillary sinus volumes have been reported to range from $18.0 \pm 6.0 \mathrm{~cm}^{3}$ to $23.6 \pm 6.4 \mathrm{~cm}^{3}$ in previous studies $[19,25,31,32,41,44,45]$. The results of the frontal sinus volumes in this study were larger than those of previous studies [19, 30, 31, 41, 45]. The mean values of the frontal sinus volumes have been reported to range from $4.0 \mathrm{~cm}^{3}$ to $11.6 \pm 4.2 \mathrm{~cm}^{3}$ in previous studies $[19,30,31,41$, 45]. The result of the sphenoid sinus volume on the left side of this study was consistent with those in the previous studies $[30,45]$. But, it was less developed on the right side. The mean values of the total volume of the sphenoid sinuses on both sides has been reported to range from $8.5 \pm 4.2 \mathrm{~cm}^{3}$ to $13.3 \pm$ $\pm 4.4 \mathrm{~cm}^{3}$ in previous studies $[19,30,41]$. The total volume of the sphenoid sinuses on both sides was consistent with those in the previous studies [19, 30, 41], but smaller than the study of Kawarai et al. [31].

\section{CONCLUSIONS}

Although they mainly measured the volumes of the paranasal sinuses in the previous studies, this study dealt with surface areas and volumetric calculations of the paranasal sinuses. The automated volume measured with volumetric measuring tools of the software is consistent with its estimated volume calculated with formula using maximum dimensions of the paranasal sinuses, suggesting that the volumetric measuring tools of the software are a sufficiently reliable technique for volume calculations.

This technique allows students, researchers, and surgeons to perform noninvasive visualisation, simulation, and precise quantitative measurements of internal structures of the body. It was developed as a complementary tool for endoscopic surgery. It could be especially preferable for the patients who could not tolerate flexible or rigid endoscopy. We have 
paved the way for developing innovative diagnostic and therapeutic modalities to ensure patient comfort and safety at all times.

\section{REFERENCES}

1. Ackerman MJ, Banvard RA (2000) Imaging outcomes from the National Library of Medicine's Visible Human Project (R). Comput Med Imag Grap, 24: 125-126. doi: 10.1016/ S0895-6111(00)00012-4.

2. Adnane C, Adouly T, Zouak A, Mahtar M (2015) Quality of life outcomes after functional endoscopic sinus surgery for nasal polyposis. Am J Otolaryng, 36: 47-51. doi: 10.1016/j. amjoto.2014.09.003.

3. Anand S, Varshney R, Frenkiel S (2011) Virtual endoscopy of the nasal cavity and the paranasal sinuses. http:// cdn.intechopen.com/pdfs/24326/InTech-Virtual_endoscopy_of_the_nasal_cavity_and_the_paranasal_sinuses. pdf. Accessed January 012015.

4. Ashburner J, Friston KJ (2000) Voxel-based morphometry: the methods. Neuroimage, 11: 805-821. doi: 10.1006/ nimg.2000.0582.

5. Barghouth G, Prior JO, Lepori D, Duvoisin B, Schnyder P, Gudinchet $F$ (2002) Paranasal sinuses in children: size evaluation of maxillary, sphenoid, and frontal sinuses by magnetic resonance imaging and proposal of volume index percentile curves. Eur Radiol, 12: 1451-1458. doi: 10.1007/s00330-001-1218-9.

6. Belina S, Cuk V, Klapan I (2009) Virtual endoscopy and $3 \mathrm{D}$ volume rendering in the management of frontal sinus fractures. Collegium Antropol, 33: 43-50.

7. Belina S, Cuk V, Klapan I, Vranjes Z, Lukinovic J (2008) Our experience with virtual endoscopy of paranasal sinuses. Coll Antropol, 32: 887-892.

8. Beylot P, Gingins P, Kalra P, Thalmann NM, Maurel W, Thalmann D, Fasel J (1996) 3D interactive topological modeling using visible human dataset. Comput Graph Forum, 15: C33-44.

9. Bisdas S, Verink M, Stieve M, Lazakidou A, Evangelou I, Becker H (2004) Three Dimensional Imaging of the Nasal Cavity and Paranasal Sinuses http://www.wseas.us/elibrary/conferences/miami2004/papers/484-415.pdf. Accessed January 012015.

10. Bookstein FL (2001) "Voxel-based morphometry" should not be used with imperfectly registered images. Neuroimage, 14: 1454-1462. doi: 10.1006/nimg.2001.0770.

11. Brambs HJ, Juchems MS (2003) Virtual endoscopy using CT scan. Minim Invasiv Ther, 12: 207-216. doi: 10.1080/13645700310015572.

12. Carrascosa P, Capunay C, Martin Lopez E, Salis G, Mazzadi S, Carrascosa J (2009) Esophageal stenosis: three-dimensional multidetector CT and virtual endoscopy. Abdom Imaging, 34: 19-25. doi: 10.1007/s00261-008-9435-1.

13. Caversaccio M, Eichenberger A, Hausler R (2003) Virtual simulator as a training tool for endonasal surgery. Am J Rhinol, 17: 283-290.

14. Chen DQ, Li B, Roche P, Huang W, Roque C, Liang ZR (2001) Feasibility studies of virtual laryngoscopy by $C T$ and MRI: from data acquisition, image segmentation, to interactive visualization. leee T Nucl Sci, 48: 51-57.
15. Dammann F (2007) Imaging of paranasal sinuses today. Radiologe, 47: 576, 78-83. doi: 10.1007/s00117-0071502-z.

16. Decraemer WF, Dirckx JJJ, Funnell WRJ (2003) Threedimensional modelling of the middle-ear ossicular chain using a commercial high-resolution X-ray CT scanner. Jaro, 4: 250-263. doi: 10.1007/s10162-002-3030-x.

17. Di Rienzo L, Tirelli GC, Turchio P, Garaci F, Guazzaroni M (2003) Comparison of virtual and conventional endoscopy of nose and paranasal sinuses. Ann Oto Rhinol Laryn, 112: 139-142.

18. Djukic V, Dudvarski Z, Arsovic N, Dimitrijevic M, Janosevic L (2015) Clinical outcomes and quality of life in patients with nasal polyposis after functional endoscopic sinus surgery. Eur Arch Oto-Rhino-L, 272: 83-89. doi: 10.1007/ s00405-014-3054-y.

19. Emirzeoglu M, Sahin B, Bilgic S, Celebi M, Uzun A (2007) Volumetric evaluation of the paranasal sinuses in normal subjects using computer tomography images: a stereological study. Auris Nasus Larynx, 34: 191-195. doi: 10.1016/j. anl.2006.09.003.

20. Finkelstein SE, Schrump DS, Nguyen DM, Hewitt SM, Kunst MF, Summers RM (2003) Comparative evaluation of super high-resolution CT scan and virtual bronchoscopy for the detection of tracheobronchial malignancies. Chest, 124: 1834-1840. doi: 10.1378/chest.124.5.1834.

21. Fujikura T, Tanaka N, Sugiura E, Ide N, Miyajima K (2009) Clinical application of virtual endoscopy as a support system for endoscopic sinus surgery. Acta Oto-Laryngol, 129 : 674-680. doi: 10.1080/00016480802360640.

22. Gilani S, Norbash AM, Ringl H, Rubin GD, Napel S, Terris DJ (1997) Virtual endoscopy of the paranasal sinuses using perspective volume rendered helical sinus computed tomography. Laryngoscope, 107: 25-29. doi: 10.1097/00005537-199701000-00008.

23. Gingins $P$, Beylot $P$, Kalra P, Thalmann NM, Maurel W, Thalmann D, Fasel J (1996) Modeling using the Visible Human Dataset http://citeseerx.ist.psu.edu/viewdoc/downl oad?doi=10.1.1.14.8218\&rep=rep1\&type=pdf. Accessed January 012015.

24. Herman GT, Liu HK (1977) Display of 3-dimensional information in computed tomography. J Comput Assist Tomo, 1: 155-160. doi:10.1097/00004728-197701000-00018.

25. Jun BC, Song SW, Park CS, Lee DH, Cho KJ, Cho JH (2005) The analysis of maxillary sinus aeration according to aging process; volume assessment by 3 -dimensional reconstruction by high-resolutional CT scanning. Otolaryngol Head Neck Surg, 132: 429-434. doi: 10.1016/j. otohns.2004.11.012.

26. Kagadis GC, Siablis D, Liatsikos EN, Petsas T, Nikiforidis GC (2006) Virual endoscopy of the urinary tract. Asian J Androl, 8: 31-38. doi: 10.1111/j.1745-7262.2006.00096.x.

27. Kapakin S (2011) The claustrum: three-dimensional reconstruction, photorealistic imaging, and stereotactic approach. Folia Morphol, 70: 228-234.

28. Kapakin S (2011) Stereolithographic biomodelling to create tangible hard copies of the ethmoidal labyrinth air cells based on the visible human project. Folia Morphol, 70: 33-40.

29. Kapakin S, Demiryurek D (2009) The reproduction accuracy for stereolithographic model of the thyroid 
gland derived from the visible human dataset. Saudi Med J, 30: 887-892.

30. Karakas S, Kavakli A (2005) Morphometric examination of the paranasal sinuses and mastoid air cells using computed tomography. Ann Saudi Med, 25: 41-45.

31. Kawarai Y, Fukushima K, Ogawa T, Nishizaki K, Gunduz M, Fujimoto M, Masuda Y (1999) Volume quantification of healthy paranasal cavity by three-dimensional CT imaging. Acta Oto-Laryngol, 540: 45-49.

32. Kaymakci M, Erel F, Bulbul E, Yazici H, Acar M, Yanik B (2015) Maxillary Sinus aeration in allergic rhinitis. J Craniofac Surg, 26: E288-E290. doi: 10.1097/ Scs. 0000000000001558.

33. Kettenbach J, Birkfellner W, Rogalla P (2008) Virtual endoscopy of the paranasal sinuses. In: Neri E, Caramella D, Bartolozzi C (eds) Image Processing in Radiology. SpringerVerlag, Berlin, Heidelberg, pp. 151-171.

34. Khan MF, Herzog C, Ackermann H, Wagner TOF, Maataoui A, Harth M, Abolmaali ND, Jacobi V, Vogl TJ (2004) Virtual endoscopy of the tracheo-bronchial system: sub-millimeter collimation with the 16-row multidetector scanner. Eur Radiol, 14: 1400-1405. doi: 10.1007/s00330-004-2325-1.

35. Klapan I, Simicic L, Risavi R, Besenski N, Pasaric K, Gortan D, Janjanin S, Pavic D (2002) Tele-3-dimensional computer-assisted functional endoscopic sinus surgery: new dimension in the surgery of the nose and paranasal sinuses. Otolaryng Head Neck, 127: 549-557. doi: 10.1067/mhn.2002.129732.

36. Levoy M (1988) Display of surfaces from volume data. leee Comput Graph, 8: 29-37. doi: 10.1109/38.511.

37. Li H, Zhang X, Song Y, Wang T, Tan G (2014) Effects of functional endoscopic sinus surgery on chronic rhinosinusitis resistant to medication. J Laryngol Otol, 128: 976-980. doi: 10.1017/S002221511400228x.

38. Mahmoudi SE, Akhondi-Asl A, Rahmani R, Faghih-Roohi S, Taimouri V, Sabouri A, Soltanian-Zadeh H (2010) Webbased interactive 2D/3D medical image processing and visualization software. Comput Methods Programs Biomed, 98: 172-182. doi: 10.1016/j.cmpb.2009.11.012.

39. Morrin MM, LaMont JT (2003) Screening virtual colonoscopy: ready for prime time? New Engl J Med, 349: 2261-2264. doi: 10.1056/NEJMe038181.

40. Phillips JE, Ji L, Rivelli MA, Chapman RW, Corboz MR (2009) Three-dimensional analysis of rodent paranasal sinus cavities from X-ray computed tomography (CT) scans. Can J Vet Res, 73: 205-211.

41. Pirner S, Tingelhoff $K$, Wagner I, Westphal R, Rilk M, Wahl FM, Bootz F, Eichhorn KW (2009) CT-based manual segmentation and evaluation of paranasal sinuses. Eur Arch Otorhinolaryngol, 266: 507-518. doi: 10.1007/ s00405-008-0777-7.

42. Pommert A, Höhne KH, Pflesser B, Riemer M, Schiemann T, Schubert R, Tiede U, Schumacher U (2000) A Highly realistic volume model derived from the visible human male. http://www.nlm.nih.gov/archive/20120702/research/ visible/vhpconf2000/ AUTHORS/HOEHNE/POMMERT.HTM. Accessed January 012015.

43. Robb RA (1990) A software system for interactive and quantitative analysis of biomedical images. 3D imaging in medicine. Springer-Verlag, Berlin, Heidelberg, pp. 333-361.

44. Sahlstrand-Johnson $P$, Jannert $M$, Strombeck A, AbulKasim K (2011) Computed tomography measurements of different dimensions of maxillary and frontal sinuses. Bmc Med Imaging, 11: 8. doi: 10.1186/1471-2342-11-8.

45. Selcuk OT, Erol B, Renda L, Osma U, Eyigor H, Gunsoy B, Yagci B, Yilmaz D (2015) Do altitude and climate affect paranasal sinus volume? J Cranio Maxill Surg, 43: 1059-1064. doi: 10.1016/j.jcms.2015.05.013.

46. Spitzer V, Ackerman MJ, Scherzinger AL, Whitlock D (1996) The visible human male: a technical report. J Am Med Inform Assn, 3: 118-130.

47. Strauss G, Limpert E, Fischer M, Hofer M, Kubisch C, Kruger A, Dietz A, Meixensberger J, Trantakis C, Strauss M, Preim B (2009) Virtual endoscopy of the nose and paranasal sinuses in real-time. Hno, 57: 789-796. doi: 10.1007/ s00106-009-1977-1.

48. Streicher J, Weninger WJ, Muller GB (1997) External markerbased automatic congruencing: a new method of 3D reconstruction from serial sections. Anat Rec, 248: 583-602.

49. Summers RM, Feng DH, Holland SM, Sneller MC, Shelhamer JH (1996) Virtual bronchoscopy: segmentation method for real-time display. Radiology, 200: 857-862.

50. Tao X, Zhu F, Chen W, Zhu S (2003) The application of virtual endoscopy with computed tomography in maxillofacial surgery. Chin Med J (Engl), 116: 679-681.

51. Tomazic PV, Neuschitzer A, Koele W, Lang-Loidolt D (2011) Feasibility of routine paranasal sinus CT-scans in preoperative transplant patients. Ann Transpl, 16: 31-35.

52. Vargas VM, Rojas JML, Del Pozo JM (2001) Automatic Three-dimensional Reconstruction of Radiological Images for Telediagnosis. http://www.cepis.org/upgrade/media/ full-2001-I..1.pdf. Accessed January 012015.

53. Wenger E, Martensson J, Noack H, Bodammer NC, Kuhn S, Schaefer S, Heinze HJ, Duzel E, Backman L, Lindenberger Uet al (2014) Comparing manual and automatic segmentation of hippocampal volumes: reliability and validity issues in younger and older brains. Hum Brain Mapp, 35: 4236-4248. doi: 10.1002/hbm.22473.

54. Wiet GJ, Yagel R, Stredney D, Schmalbrock P, Sessanna DJ, Kurzion Y, Rosenberg L, Levin M, Martin K (1997) A volumetric approach to virtual simulation of functional endoscopic sinus surgery. Stud Health Technol Inform, 39: 167-179.

55. Wood BJ, Razavi P (2002) Virtual endoscopy: a promising new technology. Am Fam Physician, 66: 107-112.

56. Wyatt CL, Ge Y, Vining DJ (2000) Automatic segmentation of the colon for virtual colonoscopy. Comput Med Imag Grap, 24: 1-9. doi: 10.1016/\$0895-6111(99)00039-7. 